\title{
Social support, quality of life and mental health status in breast cancer patients
}

\author{
Jenesh Singh Shrestha ${ }^{*}$, Alish Shrestha ${ }^{2}$, Abja Sapkota ${ }^{3}$, Rakshya Sharma ${ }^{4}$, Samip Shrestha ${ }^{1}$, Sudip Shestha ${ }^{1}$, Kapendra Sekhar Amayta ${ }^{1}$ and \\ Madhav Gautam ${ }^{1}$ \\ ${ }^{1}$ Nepal Cancer Hospital and Research Ceter, Patan 44700, Nepal \\ ${ }^{2} \mathrm{BP}$ Koirala Institute of Health Science, Dharan, Nepal \\ ${ }^{3}$ Nepal Medical College Teaching Hospital, Jorpati, Nepal \\ ${ }^{4}$ Regional Tuberculosis Center, Pokhara, Nepal
}

\begin{abstract}
Objective: In this study, Objective was to assess the social support, quality of life and mental health status in breast cancer patients. Different literatures have highlighted the breast cancer's impact on mental health, quality of life, financial status etc., but very few studies have been done particularly in Nepal to assess impact of social support and quality of life on the mental health of a breast cancer patient.

Methods: The design of the study was cross-sectional. The study was conducted from December 2015 to August 2016 . A total of 149 patients diagnosed with breast cancer who met eligibility were enrolled. We included only patients who were reachable, diagnosed with breast cancer at least for 6 months and consented to participate in the study. They were interviewed using EORTC, mMOSS-SS and HADS questionnaires through telephone interview. Statistical analysis was carried out with SPSS (version 16).

Results: For QOL, mean linear scores for the global health and functioning scale were 82.08 and 69.06 (on a scale of 0-100; higher the score, better the global health and physical function). For social support, mean linear score was 85.03 (on a scale of 0-100; higher the score, better the social support). For mental health, mean anxiety and depression score were 7.01 and 4.85 respectively (on a scale of $0-21,8$ being cut off for borderline and 11 being the cutoff for abnormal condition). Out of 149 respondents, $40.93 \%$ (61) were screened positive for depression either borderline or abnormal mood, whereas $52.34 \%$ (78) women were screened positive for anxiety either borderline or abnormal mood. Significantly less number of married woman currently living with husband had borderline plus abnormal mood. Similarly significantly higher number of woman living in nuclear family had depression. Global health scores of above mean, Social support scores of above mean and Anxiety scores of below mean had significant association with normal mood $(\mathrm{p}<0.05)$.

Conclusion: From our study, we concluded that there was a high prevalence of undiagnosed depression in breast cancer patients. Good social support, better quality of life and absence of anxiety had significant association with the better mental health status. So, regular psychiatric screening and follow up should be recommended. To improve social support; counseling of spouse, family members and friends could be done along with the patient. For the quality of life; better pain control and rehabilitation measures should be tried.
\end{abstract}

\section{Introduction and background}

Breast cancer is one of the most common cancers in women worldwide with nearly 1.7 million new cases diagnosed in 2012 (second most common cancer overall). This represents about $12 \%$ of all new cancer cases and $25 \%$ of all cancers in women [1]. It is a challenge for women as it is a life threatening disease, and needs intensive surgical and medical treatments. This new life situation may lead the women to face psychiatric co-morbidity [2]. Depression and anxiety are common among people diagnosed with cancer [3]). The patients with untreated depression or anxiety are less likely to take their cancer treatment medication and continue healthy habits because of fatigue and lack of motivation.

So, the current focus of cancer treatment should not only be the illness control, but also should be on the mental health and general well being of the patients. Quality of life would be the appropriate term to use when it comes to the general well being of patients. It encompasses several aspects such as physical, psychological, cognitive, symptom, social functioning, global health, etc. [4]. Because It is one of the most important patient-reported outcomes, measurement of QoL at diagnosis may provide useful information regarding patient's preferences and prognosis, while follow-up measurements may indicate acceptance, adaptation and adverse effects of disease and therapy.

On the other hand Social support is defined as any type of communication, in the forms of physical or psychological assistance, for someone to feel to have more self-control during difficult times [5]. Studies have shown that the social support felt or perceived by the individual produces the positive impact [6,7]. Perceived social support is negatively correlated with psychological distress and suicidal thought in cancer patients [8].

Correspondence to: Jenesh Singh Shrestha, Intensive Care Unit, Nepal Cancer Hospital and Research Center, Harisiddhi Laltitpur, Nepal, Tel: 9779842349528; E-mail: jeneshshrehstha8671@gmail.com

Key words: social support, quality of life, mental health, breast cancer

Received: January 07, 2017; Accepted: January 30, 2017; Published: February 01,2017 
Because breast cancer is the second most common cancer in women in Nepal [9]. Multiple studies have been done in Nepal to the assess the epidemiology, clinical profile, treatment, quality of life and other comorbidities [10]. But precise assessment and the effect of the quality of life and social support on the mental health status among breast cancer patient is lacking in Nepal.

In our study, we evaluated perceived social support using mMOSSSS (five item modified medical outcome study for social support survey), the quality of the patients using the EORTC QLQ b-30 (European organization of research and treatment of cancer quality of life questionnaire) and screened for anxiety and depression using HADS (Hospital Anxiety Depression Scale). The aim of this study was to assess the perceived social support, quality of life, and mental health status of the patient and find out the association between them if any.

\section{Methods}

We designed a cross-sectional study. The study was conducted at the Nepal Cancer Hospital and Research Center. We conducted the study from December 2015 to August 2016. Verbal consent was taken from every patient.

Out of 319 total registered cases from (medical record directory of the hospital) only 149 patients were enrolled in the study who met eligibility criteria.

\section{Eligibility criteria}

We included patients who consented, who were diagnosed with cancer at least for 6 months, were currently following up for any form of treatment, and were responding to treatment, stable disease, progressing, treatment failure or had recurrent disease after complete resolution.

We excluded those patients who were diagnosed with any mood disorder before cancer, uncontrolled chronic medical illness (not as a result of cancer or its treatment related complications), recent medical illness in last one month requiring inpatient hospital admission for at least a week (not as a result of cancer and its treatment related complications) or who were labeled as cured.

\section{Study tools}

Quality of life was measured using the Quality of Life Questionnaire QLQ-C30, Version 3.0 of the EORTC Study Group on Quality of Life [9]. The QLQ-C30 is composed of both multi-item scales and singleitem measures. These include a global health status/QoL scale and five functional scales evaluating physical functioning, role functioning, emotional functioning, cognitive functioning, and social functioning. All the measures range in score from 0 to 100 . Higher mean scores on these scales represent better functioning and QoL.

Anxiety and depression were assessed using the Anxiety and Depression Scale (HADS). It is a self-administered questionnaire that screens anxiety (7 items) and depressive (7 items) symptoms. It has demonstrated good reliability. The anxiety (HADS-A) and depression (HADS-D) subscales are scored from 0 to 3 (four-point scales), giving maximum scores of 21 for anxiety and depression respectively [11].

Perceived social support was assessed using five items MOS-SSS (modified medical outcome study for social support survey) scale. Each item is scored on a five-point scale and the items are summed for a total score ranging from 5-25. It has demonstrated good reliability [12]. All the scales were transformed in 0 to 100 score. Higher mean scores on these scales represent better social support.

The final tool consisted of 49 questionnaire items (30 from EORTC b30, 5 from mMOSS-SS, and 14 from HADS). The tools were was available in the English language. So, they were translated into Nepali language by a professional. Translation of the tools from Nepali to English were done again to ensure that meaning didn't change. Final tools were tested in 6 patients. The reliability coefficient of each tool was checked with the help of Cronbach's alpha. The reliability coefficient were $0.83,0.86$ and 0.81 for EORTC, mMOSS-SS and HADS respectively for the translated tool in Nepali. Because, Cornbach's alpha was found to be significant for each tool, no modification in the questionnaire was required.

\section{Operation modality}

Data gathering was done in three phases for each and every individual case. In the first phase, data were taken from inpatient record files for demographic profile, clinical profile and information about the next follow up.

Secondly, during the follow up visit, patients were explained about the objective of the study, risk/benefit of participation, and confidentiality. Verbal informed consent was taken who were eligible and willing to participate.

In the last phase of the study, the telephone interview was done with those who were eligible, enthusiastic and consented verbally during their follow up visit. Nepali translated version of EORTC QLQ C-30 (version-3), mMOS-SS (five item modified medical outcome study for social support survey) and HADS questionnaire for anxiety and depression screening were used.

Considering the cultural background, to make the interview less stressful and more comfortable for patients while answering sensitive questions regarding sexual health, we choose to do telephone instead of a face to face interview.

We downloaded EORTC QLQ version-3 from the European Organization of Research and treatment cancer. We have cited them in the reference section below. Use of mMOS-SS and HADS questionnaire were waived by their developers. So, the citation was not required for the latter two tools.

\section{Ethics}

The respondents were explained about the objective, risk and benefits of the study during follow up. Verbal informed consent was taken for the phone interview.

\section{Analysis}

Data were entered into the excel. Analysis was done in SPSS. The data were checked for normality by using the Shapiro-Wilk test. Chisquare testing was done to analyze the association between variables considering the level of significance $\mathrm{p}<0.05$. And for the data which showed statistical significance in chi-square testing, we used binary logistic regression to further analyze the association.

\section{Results and discussion}

On average, the prevalence of depression and anxiety among cancer patients ranged from 20 to $30 \%$, according to the study published in Asia Pacific Journal of oncology [13] and BMJ [14]. Where as depression was present in $28.0 \%$ of cancer patients and $40.0 \%$ of cancer patients had anxiety as per HADS according to a study done 
in Nepal [15]. When we screened patients for mental health status, $61(40.93 \%)$ of breast patients were positive either for borderline or abnormal depression, whereas 78 (52.34\%) of patients were positive either borderline or abnormal anxiety. This showed that the prevalence of undiagnosed depression and anxiety was higher in breast cancer patients when compared to other cancer as shown in the Table 1.

In a study done by Zhen Gou et al. concerning QoL of patients undergoing radiotherapy at People's Republic of China, global health status/QoL score was 61.31, function (55.56) and symptom score (29.42) [16]. In our study mean global health score, functioning scale, social support score, anxiety and depression score were $82.08,69.06$, $85.03,7.01$ and 4.85 respectively as listed in the Table 2. So, Global health and physical functioning of Nepali women with breast cancer was found slightly higher when compared to other type of cancer.

In a study published in the Caspian Journal of Internal Medicine [17], the spectrum of depression (symptomatic plus mild depression) was $48 \%$ and the spectrum of anxiety (symptomatic plus mild anxiety) was $46 \%$ which was comparable to the results of our study. So, while screening the depression and anxiety not only moderate, symptomatic or severe disease should be of concern for physician, but also the use of appropriate screening tools to address and treat the borderline cases should be done to prevent further progression of the mental illness.

The average scores of both HADS depression subscale and anxiety subscale for the subjects in this study were lower than the threshold score for HADS defined anxiety or depressive disorder [11].
While associating demographic and clinical profile of the breast cancer patients we found that marital status of the patient and the type of family had a significant association on the mood of the patients. Women who were married and lived in a joint family were screened to have a normal mood when compared to the women who were unmarried and lived in a nuclear family with chi square $\mathrm{p}$ values $<0.05$. When we applied regression statistics to the associations, we found that $p$ value after binary logistic regression was statistically significant, i.e. $\mathrm{p}<0.05$ in the women who lived in a joint family. The adjusted odds ratio was found to be 0.46 , i.e. women who lived in a joint family had low odds of testing positive screen for abnormal mood compared to the women who lived in a nuclear family as shown in the Table 3.

Regression analysis of marital status was non- significant because the level of significance demanded by binary logistic regression was very high i.e., $\mathrm{p}<0.001$. Because of insufficient data in our study, we recommend this parameter to be tested in a large scale stratified analysis in future.

Many studies have shown that QoL of cancer patients was negatively correlated with depression and anxiety [18,19]. A German study highlighted that anxiety and depression were associated not only with the psychosocial but also the somatic aspects of QoL of breast cancer patients [20]. Two previous Chinese studies reported a correlation between anxiety and depression with poorer quality of life in breast cancer patients under chemotherapy or even post therapy [21]. When we tried to associate QOL (Global Health), perceived

Table 1. HADS A (Anxiety) and D (Depression) positive screening.

\begin{tabular}{|l|l|l|}
\hline & HADS D normal mood & HADS D borderline + abnormal mood \\
\hline Frequency & $88(59.06 \%)$ & $61(40.93 \%)$ \\
\hline Frequency & HADS A no anxiety & HADS A borderline + abnormal anxiety \\
\hline
\end{tabular}

Table 2. Mean calculated score of Global Health, Social Support, Functioning scale and Hospital Anxiety and Depression scale.

\begin{tabular}{|l|c|c|c|c|}
\hline & Global Health & Functioning scale & Social support & HADS A (anxiety) \\
\hline Mean & 82.08 & 69.06 & 85.03 & 7.01 \\
\hline
\end{tabular}

Table 3. Showing Chi square and Binary logistic regression application to determine the association between Clinical profiles and Depression.

\begin{tabular}{|c|c|c|c|c|c|c|}
\hline \multicolumn{2}{|l|}{ Variables } & \multirow{2}{*}{$\begin{array}{c}\text { HADS D Normal mood } \\
45 \\
\end{array}$} & \multirow{2}{*}{$\begin{array}{c}\text { HADS D Border } \\
\text { line+abnormal } \\
31\end{array}$} & \multirow{3}{*}{$\begin{array}{c}\text { Chi square } \mathbf{P} \\
\text {-value } \\
\mathrm{P}>0.05\end{array}$} & \multirow{3}{*}{$\begin{array}{c}\text { Binary logistic regression } \\
\text { P-value } \\
- \\
\end{array}$} & \multirow{3}{*}{$\begin{array}{c}\text { Adjusted Odds Ratio } \\
-\end{array}$} \\
\hline \multirow[t]{2}{*}{ Age at diagnosis } & Up to 50 & & & & & \\
\hline & $>50$ & 43 & 30 & & & \\
\hline \multirow[t]{2}{*}{ Stage at diagnosis } & Up to stage ii & 54 & 33 & \multirow[t]{2}{*}{$\mathrm{P}>0.05$} & \multirow[t]{2}{*}{-} & \multirow[t]{2}{*}{-} \\
\hline & More than stage ii & 34 & 28 & & & \\
\hline \multirow[t]{2}{*}{ Type of Treatment } & $\begin{array}{l}\text { Surg only or } \\
\text { Surg + chemo or } \\
\text { Surg + radio }\end{array}$ & 16 & 11 & \multirow[t]{2}{*}{$\mathrm{P}>0.05$} & \multirow[t]{2}{*}{-} & \multirow[t]{2}{*}{-} \\
\hline & Surg + chem + radio & 72 & 50 & & & \\
\hline \multirow[t]{2}{*}{ Menstrual status } & Menstruating & 48 & 40 & \multirow[t]{2}{*}{$\mathrm{P}>0.05$} & \multirow[t]{2}{*}{-} & \multirow[t]{4}{*}{-} \\
\hline & Menopause & 40 & 21 & & & \\
\hline \multirow[t]{2}{*}{ Employment } & Not employed & 65 & 39 & \multirow{2}{*}{$\mathrm{P}>0.05$} & \multirow[t]{2}{*}{-} & \\
\hline & Employed & 23 & 22 & & & \\
\hline \multirow[t]{2}{*}{ Marital status } & $\begin{array}{l}\text { Single/ widowed/ not living } \\
\text { with a husband }\end{array}$ & 4 & 15 & \multirow[t]{2}{*}{$\mathrm{P}<0.05$} & \multirow[t]{2}{*}{ P statistically insignificant } & \multirow[t]{2}{*}{-} \\
\hline & $\begin{array}{l}\text { Married and living with } \\
\text { husband }\end{array}$ & 84 & 46 & & & \\
\hline \multirow[t]{2}{*}{ Type of family } & Nuclear & 26 & 29 & \multirow[t]{2}{*}{$\mathrm{P}<0.05$} & \multirow[t]{2}{*}{$\mathrm{P}<0.05$} & \multirow[t]{2}{*}{0.46} \\
\hline & $\begin{array}{l}\text { Non-Nuclear } \\
\text { (Joint+third generation) }\end{array}$ & 62 & 32 & & & \\
\hline
\end{tabular}


Table 4. Showing Chi square and Binary logistic regression to determine the association between Global health and Mental health.

\begin{tabular}{|l|c|c|c|}
\hline Global Health score & $\begin{array}{c}\text { HADS D } \\
\text { Normal }\end{array}$ & HADS D borderline+abnormal & chi square p value \\
\hline Below mean & 36 & 36 & Pinary log regression p value \\
\hline Above mean & 52 & 25 & \\
\hline & 88 & 61 & \\
\hline
\end{tabular}

Table 5. Showing Chi square and Binary logistic regression to determine the association between social support and mental health.

\begin{tabular}{|l|c|c|c|}
\hline Global Health score & $\begin{array}{c}\text { HADS D } \\
\text { Normal }\end{array}$ & HADS D borderline+abnormal & chi square p value \\
\hline Below mean & 34 & 37 & Binary log regression p value \\
\hline Above mean & 54 & 24 & \\
\hline & 88 & 61 & P statistically insignificant \\
\hline
\end{tabular}

Table 6. Showing Chi square and Binary logistic regression to determine the association between anxiety and mental health.

\begin{tabular}{|l|c|c|c|}
\hline Global Health score & $\begin{array}{c}\text { HADS D } \\
\text { Normal }\end{array}$ & HADS D borderline+abnormal & chi square p value \\
\hline Below mean & 51 & 24 & Binary log regression p value \\
\hline Above mean & 37 & 37 & \\
\hline & 88 & 61 & P statistically insignificant \\
\end{tabular}

social support and Anxiety with the depression we found chi square statistics was statistically significant among them with $\mathrm{p}<0.05$ as shown in Tables 4-6. In general, the level of perceived social support measured using MSPSS was relatively good among the subjects in the our study in comparison with the other studies $[4,22]$. In our study, we demonstrated the negative association between QoL and depression. The higher level of perceived social support among the breast cancer subjects was associated with better mental health status. This finding is similar to several previous studies [23].

We applied binary logistic regression in all parameters which were statistically significant in chi square testing. But the level of significance demanded by binary logistics regression was very high i.e., $\mathrm{p}<0.001$. So, data were insufficient for us to draw any conclusion after regression analysis. We recommend stratified analysis in larger scale in the future to find the exact association and the odds ratio as in Tables 4-6.

\section{Conclusion}

We concluded that the prevalence of undiagnosed depression and anxiety was high in breast cancer patients i.e., $40.93 \%$ and $52.34 \%$ resepectively. Good social support, better quality of life and absence of anxiety had significant association with the better mental health status. So, regular psychiatric screening and follow up should be recommended to each and every patient regardless of the clinical profile of the disease. For the improvement of social support; counseling of spouse, family members and friends could be done along with the patient. For the quality of life; better pain control and rehabilitation measures should be tried.

\section{Funding}

Study was not funded. It was conducted solely in the interest of authors for future betterment in the management of breast cancer struggling patients.

\section{Acknowledgement}

We acknowledge nursing team of Nepal Cancer Hospital and Research Center particularly Nurse Jamuna Maharjan, Nurse Ambika Maharjan and the Lobby staff Ms. Binu Maharjan. Without their contribution it would have been very difficult for us to conclude the study.

\section{Conflict of interest}

All the authors had contributed and played a significant role from their side in the study. There was no any conflict of interest declared.

\section{References}

1. Cancer Incidence and Mortality Worldwide (2015) IARC CancerBase No. 11. http:// globocan.iarc.fr

2. Glanz K, Lerman C (1992) Psychosocial impact of breast cancer: a critical review. Ann Behavioral Med 14: 204-212.

3. Baumeister H, Kriston L, Bengel J, Härter M (2010) High agreement of self-report and physician-diagnosed somatic conditions yields limited bias in examining mental physical comorbidity. J Clin Epid 63: 558-565.

4. Aaronson NK, Ahmedzai S, Bergman B, Bullinger M, Cull A, et al. (1993) The European Organisation for Research and Treatment of Cancer QLQ-C30: A qualityof-life instrument for use in international clinical trials in oncology. J Natl Cancer Inst 85: 365-376. [Crossref]

5. Albrecht TL, Adelman MB (1987) Communicating social support: A theoretical perspective. In: Albrecht TL, Adelman MB, editors. Communicating social support. Newbury Park, CA: Sage, pp. 18-39.

6. Langford CP, Bowsher J, Maloney JP, Lillis PP (1997) Social support: a conceptua analysis. $J$ Adv Nurs 25: 95-100. [Crossref]

7. Trevino KM, Fasciano K, Block S, Prigerson HG (2013) Correlates of social support in young adults with advanced cancer. Support Care Cancer 21: 421-429. [Crossref]

8. Ceyhan M, Sengül B, Kaya V, Ahmet Sen C, Kaya K (2014) Association between suicidal ideation and behavior, and depression, anxiety, and perceived social support in cancer patients. Med Sci Monit 20: 329-336.

9. Pradhananga KK, Baral M, Shrestha BM (2009) Multi-institution hospital-based cancer incidence data for Nepal: an initial report. Asian Pac J Cancer Prev 10: 259262. [Crossref]

10. Shrestha JS, Shrestha A, Shrestha S, Shrestha S, Sharma TR, et al. (2016) Epidemiology and Clinical Profile of Breast Cancer in Central Nepal. Ann Breast Cancer Res 1(1): 1005.

11. Zigmond AS, Snaith RP (1983) The hospital anxiety and depression scale. Acta Psychiatr Scand 67: 361-370. [Crossref]

12. McCarrier KP, Bushnell D, Martin M, Paczkowski R, David R, et al. (2011) Validation and Psychometric Evaluation of A 5-Item Measure of Perceived Social Support. Health Research Associates, Inc, Seattle, WA USA; 2Eli Lilly and Company, Indianapolis, IN, USA 
13. Zainal NZ, Nik-Jaafar NR, Baharudin A, Sabki ZA, Ng CG (2013) Prevalence of depression in breast cancer survivors: a systematic review of observational studies. Asian Pac J Cancer Prev 14: 2649-2656. [Crossref]

14. Burgess C, Cornelius V, Love S, Graham J, Richards M, et al. (2005) Depression and anxiety in women with early breast cancer: five year observational cohort study. $B M J$ 330: 702. [Crossref]

15. Thapa P, Rawal N, Bista Y (2010) A study of depression and anxiety in cancer patients. Nepal Med Coll J 12: 171-175. [Crossref]

16. Zhen Gou J, Zheng Y, Qian JX, Gu XQ, Wang JJ (2013) Study on factors affecting the quality of life to cancer patients at the community level in Shaghai. Zhonghua Liu Xing Bing Xue Za Zhi 26 (100): 761-766.

17. Nikbakhsh N, Moudi S, Abbasian S, Khafri S (2014) Prevalence of depression and anxiety among cancer patients. Caspian J Intern Med 5(3): 167-170. [Crossref]

18. So WK, Chow KM, Chan HY, Choi KC, Wan RW, et al. (2014) Quality of life and most prevalent unmet needs of Chinese breast cancer survivors at one year after cancer treatment. Eur J Oncol Nurs 18: 323-328. [Crossref]

19. Reich M, Lesur A, Perdrizet-Chevallier C (2008) Depression, quality of life and breast cancer: a review of the literature. Breast Cancer Res Treat 110: 9-17.

20. Schleife H, Sachtleben C, Barboza CF, Singer S, Hinz A (2014) Anxiety, depression, and quality of life in German ambulatory breast cancer patients. Breast Cancer 21 : 208-213.

21. So WKW, Chow KM, Chan HYL, Choi KC, Wan RWM, et al. (2014) Quality of life and most prevalent unmet needs of Chinese breast cancer survivors at one year after cancer treatment. Eur J Oncol Nurs 18: 323e328.

22. Ceyhan M, Sengül B, Kaya V, Ahmet Sen C, Kaya K (2014) Association between suicidal ideation and behavior, and depression, anxiety, and perceived social support in cancer patients. Med Sci Monit 20: 329-336.

23. Ng CG, Mohamed S, See MH, Harun F, Dahlui M, et al. (2015) Anxiety, depression, perceived social support and quality of life in Malaysian breast cancer patients: a 1-year prospective study. Health Qual Life Outcomes 13: 205. [Crossref]

Copyright: $@ 2017$ Shrestha JS. This is an open-access article distributed under the terms of the Creative Commons Attribution License, which permits unrestricted use, distribution, and reproduction in any medium, provided the original author and source are credited. 